This document is the Accepted Manuscript version of a Published Work that appeared in final form in Macromolecules, copyright (c) 2018 American Chemical Society after peer review and technical editing by the publisher.

To access the final edited and published work see https://doi.org/10.1021/acs.macromol.8b01801

\title{
Uniaxial and Mixed Orientations of Poly(ethylene oxide) in Nanoporous Alumina Studied by X-ray Pole Figure Analysis
}

Cui Su${ }^{1,5}$, Guangyu Shi ${ }^{1,5}$, Xiaolu Li ${ }^{2}$, Xiuqin Zhang ${ }^{2}$, Alejandro J. Müller ${ }^{3,4}$, Dujin Wang ${ }^{1,5}$ and Guoming Liu*1

1. CAS Key Laboratory of Engineering Plastics, CAS Research/Education Center for Excellence in Molecular Sciences, Institute of Chemistry, Chinese Academy of Sciences, Beijing 100190, China

2. Beijing Key Laboratory of Clothing Materials R \& D and Assessment, Beijing Engineering Research Center of Textile Nanofiber, School of Materials Science \& Engineering, Beijing Institute of Fashion Technology, Beijing 100029, China

3. POLYMAT and Polymer Science and Technology Department, Faculty of Chemistry, University of the Basque Country UPV/EHU, Paseo Manuel de Lardizabal 3, 20018 Donostia-San Sebastián, Spain.

4. IKERBASQUE, Basque Foundation for Science, Bilbao, Spain.

5. University of Chinese Academy of Sciences, Beijing 100049, China 


\section{ABSTRACT:}

The orientation of polymers under confinement is a basic, yet not fully understood phenomenon. In this work, the texture of poly(ethylene oxide) (PEO) infiltrated in nanoporous anodic alumina oxide (AAO) templates was investigated by X-ray pole figures. The influence of geometry and crystallization conditions, such as pore diameter, aspect ratio, and cooling rates, was systematically examined. All the samples exhibited a single, volume-dependent crystallization temperature $\left(T_{\mathrm{c}}\right)$ at temperatures much lower than that exhibited by bulk PEO, indicating "clean" microdomains without detectable heterogeneous nucleation. An "orientation diagram" was established to account for the experimental observations. Under very high cooling rates (quenching), crystallization of PEO within AAO was nucleation-controlled, adopting a random distribution of crystallites. Under low cooling rates, growth kinetics played a decisive role on the crystal orientation. A relatively faster cooling rate $\left(10^{\circ} \mathrm{C} / \mathrm{min}\right)$ and/or smaller pores lead to the $<120>^{*} \|$ pore axis $(\overrightarrow{\boldsymbol{n}})$ mode (uniaxial orientation). When the cooling rate was lower $\left(1{ }^{\circ} \mathrm{C} / \mathrm{min}\right)$, and/or the pores were larger, a mixed orientation, with a coexistence of $<120>* \| \overrightarrow{\boldsymbol{n}}$ and $<010>* \| \overrightarrow{\boldsymbol{n}}$, was observed. The results favor the kinetic model where the fastest growth direction tends to align parallel to the pore axis.

\section{INTRODUCTION}

The crystallization behavior of polymers under confinement are attracting increasingly attention because it provides a model system to understand basic questions about polymer nucleation and growth kinetics, as well as its close relevance to modern nanotechnology, such as nanofabrication and functional nanodevices. ${ }^{1,2,3,4,5,6,7}$ Nanoporous anodic alumina oxide (AAO) templates have been widely used to construct a uniform confined environment since the development of electrochemical method to fabricate well-ordered arrays. ${ }^{8}$ The nucleation and crystallization of polymers within AAO templates has been the subject of several reviews. ${ }^{2,9,10}$

Two general observations have been reported for infiltrated polymers within AAO, i.e., altering of the 
nucleation mechanism and anisotropic crystal growth. Much larger supercoolings are observed for polymers infiltrated in $\mathrm{AAO}$, indicating a change of nucleation mechanism from heterogeneous to homogenous or surface nucleation. ${ }^{11,12}$ The presence of fractionated crystallization in infiltrated polymers in AAO templates, where several crystallization peaks are observed upon cooling from the melt ${ }^{5}$ has been recently assigned to the percolation of surface film residues that have not been completely removed during the cleaning procedure performed after infiltration. ${ }^{13}$

Crystal orientation within AAO nanopores is another interesting phenomenon that has also attracted much attention. Polymer chains within the crystals typically align with their chain axis (i.e., $c$ axis) perpendicular to the pore axis (defined as $\boldsymbol{c} \perp \overrightarrow{\boldsymbol{n}}$, hereafter). ${ }^{14}$ This has been explained by a "kinetic effect" by Steinhart et al., ${ }^{15}$ i.e., those crystal lamellae with growing direction not parallel to the pore axis are blocked by the wall, while the crystal lamellae with the $\langle h k 0>*$ direction parallel to the pore axis are free to grow. It has been realized that the orientation mode of "c $\perp \overrightarrow{\boldsymbol{n}}$ " is a very "weak" restriction for crystal growth, usually resulting in a low degree of anisotropy. ${ }^{13}$

A geometrically similar 2D confined system is the well-studied cylinder-forming block copolymers, however, the orientation model was quite different with respect to the "c $\perp \overrightarrow{\boldsymbol{n}}$ " mode. ${ }^{16}$ Huang et al. studied the crystal orientation of PEO block nanocylinders (with a diameter of $13.7 \mathrm{~nm}$ ) within a PS matrix in a PEO- $b$-PS/PS blend. ${ }^{17}$ It was shown that the crystallization temperature played a significant role in the crystal orientation. At very low crystallization temperature $\left(T_{\mathrm{c}}\right)$, PEO crystals were randomly oriented within the confined cylinders. Upon increasing the crystallization temperature $\left(-30{ }^{\circ} \mathrm{C} \leq T_{\mathrm{c}} \leq 0{ }^{\circ} \mathrm{C}\right)$, the crystal orientation changed to be inclined with respect to the cylinder axis. When the sample was crystallized at $T_{\mathrm{c}} \geq 2{ }^{\circ} \mathrm{C}$, a uniaxial orientation with the $\left\langle 120>^{*}\right.$ direction parallel to the pore axis was found. This orientation mode resulted from the alignment of maximum PEO crystal growth direction $\left(<120>^{*}\right)$ with the channel axis.

Table 1 summarizes the orientation of polymer crystals confined in AAO nanopores. Except for several 
particular reports, ${ }^{12,15,18,19}$ the majority of the systems exhibit uniaxial orientation or a mixed structure with two types of uniaxial orientations. It is noticed that the structure of many systems could be explained by the alignment of the fastest growth direction with the pore axis, such as in $\mathrm{PEO}^{20,21,22}$ and in PE. ${ }^{23,24}$ Two modes of crystal orientation were identified in PEO infiltrated within AAO, namely, perpendicular orientation with the normal direction of (120) plane (i.e., $<120>^{*}$ direction) aligning parallel to the pore axis and tilt orientation with the $<120>^{*}$ tilted $45^{\circ}$ away from the pore axis..$^{20,21}$ Two types of orientation were also observed in poly(caprolactone) (PCL), ${ }^{13}$ isotactic polypropylene (iPP), ${ }^{13}$ PVDF, ${ }^{25,26}$ and syndiotactic polypropylene (sPP). ${ }^{27}$ There is still a lack of a reasonable explanation of the coexistence of different orientation modes.

Thermodynamics or surface effects play a role in the crystal orientation as well. When the size of the AAO pores is smaller than the contour length of the low molecular weight poly(ethylene oxide) (PEO), the polymer crystallized into its thermodynamic stable structure by maintaining the extended chain crystal with polymer chains align parallel to the AAO axis. ${ }^{22}$ The "parallel orientation" observed in infiltrated syndiotactic polystyrene (sPS) within AAO templates was explained by a surface nucleation effect. ${ }^{18}$

Apart from the lack of a general model for the orientation of polymers confined in AAO templates, it should be noted that the characterization of the texture is frequently inadequate in the literature. The most commonly applied two-dimensional X-ray diffraction method, only provides limited information of the reciprocal space. Further, the influence of the pore diameter, aspect ratio, as well as crystallization conditions have not been quantitatively investigated yet. In this work, X-ray pole figure measurements are employed to characterize infiltrated PEO in AAO templates to get a full picture of the crystal orientation. It was shown that PEO predominately adopted a uniaxial orientation in AAO with the $\langle 120\rangle *$ direction parallel to the pore axis $(\overrightarrow{\boldsymbol{n}})$. Smaller diameter and higher aspect ratio resulted in higher degrees of orientation. Cooling rate played the most significant role in the crystal orientation. A "tilted orientation" of PEO was confirmed, which is in line with the 
report of Liu and Chen. ${ }^{20,21}$ However, a new explanation was proposed to justify the multiple uniaxial orientational

phenomena by investigating the influence of geometry and crystallization conditions.

Table 1. Summary of the Orientation of Infiltrated Polymer Crystallites within AAO Nanopores.

\begin{tabular}{|c|c|c|c|c|c|c|}
\hline Polymer & Infiltration method & $\begin{array}{l}\text { Surface } \\
\text { layer }^{a}\end{array}$ & $\begin{array}{l}\text { Crystallization } \\
\text { condition }\end{array}$ & Orientation $^{b}$ & $\Phi_{\mathrm{AAO}}(\mathrm{nm})$ & Ref. \\
\hline \multirow{6}{*}{ PEO } & melt nanorod & $\mathrm{N}$ & & \begin{tabular}{l||l}
$<120>*$ & $\overrightarrow{\boldsymbol{n}}$ \\
\end{tabular} & $30,60 \& 100$ & \multirow{2}{*}{22} \\
\hline & melt, nanorod & $\mathbf{N}$ & & \begin{tabular}{l||l}
$c$ & $\overrightarrow{\boldsymbol{n}}$ \\
\end{tabular} & 10 & \\
\hline & solution, nanotube & $\mathrm{N}$ & $\begin{array}{l}-40{ }^{\circ} \mathrm{C}, \quad-20^{\circ} \mathrm{C}, \\
0{ }^{\circ} \mathrm{C} \text {, and } 20^{\circ} \mathrm{C}\end{array}$ & $<120>* \| \overrightarrow{\boldsymbol{n}}$ or tilted $45^{\circ}$ & $23 \& 89$ & 20 \\
\hline & melt, nanorod & $\mathrm{N}$ & $\begin{array}{l}-40^{\circ} \mathrm{C}, \quad-20^{\circ} \mathrm{C}, \\
0{ }^{\circ} \mathrm{C} \text {, and } 20^{\circ} \mathrm{C}\end{array}$ & $<120>* \| \overrightarrow{\boldsymbol{n}}$ or tilted $45^{\circ}$ & $23 \& 89$ & 21 \\
\hline & melt & $\mathrm{N}$ & & $c \perp \vec{n}$ & 20 & 12 \\
\hline & melt, nanotube & $\mathrm{N}$ & & $<120>* \# \overrightarrow{\boldsymbol{n}}$ & 400 & 19 \\
\hline \multirow{3}{*}{ PE } & melt, nanorod & $\mathrm{N}$ & $1^{\circ} \mathrm{C} / \mathrm{min}$ & mainly $\overrightarrow{\boldsymbol{b}} \| \overrightarrow{\boldsymbol{n}}$ & 60 & 23 \\
\hline & melt, nanorod & $\mathrm{N}$ & $0.5^{\circ} \mathrm{C} / \mathrm{min}$ & $b \| \vec{n}$ & 15 to 220 & 24 \\
\hline & melt, nanorod & $\mathrm{Y}$ & $120^{\circ} \mathrm{C}$ & mainly $\overrightarrow{\boldsymbol{b}} \| \overrightarrow{\boldsymbol{n}}$ & 200 & 28 \\
\hline \multirow{6}{*}{ PVDF } & melt, nanotube & $\mathrm{N}$ & & \begin{tabular}{|l||l}
$\boldsymbol{b}$ & $\overrightarrow{\boldsymbol{n}}$ \\
\end{tabular} & $400 \& 1000$ & 14 \\
\hline & melt, nanorod \& & $\mathrm{N}$ & $1^{\circ} \mathrm{C} / \mathrm{min}$ & \begin{tabular}{l||l}
$<\mathrm{hk} 0>^{*}$ & $\overrightarrow{\boldsymbol{n}}$ \\
\end{tabular} & \multirow{2}{*}{$35 \& 400$} & \multirow{2}{*}{15} \\
\hline & nanotube & $\mathrm{Y}$ & $1{ }^{\circ} \mathrm{C} / \mathrm{min}$ & $<020>*$ & & \\
\hline & melt, nanotube & $\mathrm{N}$ & $\begin{array}{c}1{ }^{\circ} \mathrm{C} / \mathrm{min}, \\
136^{\circ} \mathrm{C}, 140^{\circ} \mathrm{C} \text { or } \\
152^{\circ} \mathrm{C}\end{array}$ & $<020>*$ or $<110>* \| \overrightarrow{\boldsymbol{n}}$ & 400 & 25 \\
\hline & melt, nanotube & $\mathrm{N}$ & $1^{\circ} \mathrm{C} / \min$ & $\begin{array}{c}<020>* \| \overrightarrow{\boldsymbol{n}} \text { (majority) } \\
\quad \text { or }<110>* \\
\end{array}$ & 400 & 26 \\
\hline & solution, nanorod, & $\mathrm{Y}$ & $60{ }^{\circ} \mathrm{C}$ & $b \| \vec{n}$ & $150-200$ & 29 \\
\hline \multirow{4}{*}{ P(VDF-TrFE) } & $\begin{array}{c}\text { melt, nanorod \& } \\
\text { nanotube }\end{array}$ & $\mathrm{N}$ & $2^{\circ} \mathrm{C} / \mathrm{min}$ & $<200>*$ or $<110>* \| \overrightarrow{\boldsymbol{n}}$ & 400 & 30 \\
\hline & solution, nanorod & $\mathrm{Y}$ & $135^{\circ} \mathrm{C}$ & $a \| \vec{n}$ & $40,60 \& 80$ & 31 \\
\hline & melt, nanorod & $\mathrm{Y}$ & $125^{\circ} \mathrm{C}$ & $c \perp \vec{n}$ & $15 \& 40$ & \multirow{2}{*}{32} \\
\hline & melt, nanotube & $\mathrm{Y}$ & $125^{\circ} \mathrm{C}$ & random & 200 & \\
\hline \multirow{2}{*}{$s \mathrm{PP}$} & \multirow{2}{*}{ melt, nanorod } & \multirow{2}{*}{$\mathrm{N}$} & \multirow{2}{*}{ slow cooling } & $<020>^{*}|| \overrightarrow{\boldsymbol{n}}$ & 110,300 & \multirow{2}{*}{27} \\
\hline & & & & $<200>^{*}$ or $<020>* \| \overrightarrow{\boldsymbol{n}}$ & 30 & \\
\hline \multirow{3}{*}{$i \mathrm{PP}$} & \multirow{3}{*}{ melt, nanorod } & \multirow{3}{*}{$\mathrm{N}$} & & \begin{tabular}{l||l}
$\boldsymbol{a}^{*}$ or $\boldsymbol{b}^{*}$ & $\overrightarrow{\boldsymbol{n}}$ (mixed) \\
\end{tabular} & 15,40 & \multirow{2}{*}{33} \\
\hline & & & & random $(200 \mathrm{~nm})$ & 200 & \\
\hline & & & $1^{\circ} \mathrm{C} / \mathrm{min}$ & \begin{tabular}{l||l|}
$a^{*}$ or $b^{*}$ & $\vec{n}$ (mixed) \\
\end{tabular} & 20 to 400 & 13 \\
\hline \multirow{2}{*}{ PCL } & melt, nanorod & $\mathrm{N}$ & $1^{\circ} \mathrm{C} / \mathrm{min}$ & $\begin{array}{c}\text { ФАAO }>40 \mathrm{~nm}, \boldsymbol{c} \perp \overrightarrow{\boldsymbol{n}} \\
\Phi \mathrm{AAO} \leq 40 \mathrm{~nm}, \boldsymbol{c} \perp \overrightarrow{\boldsymbol{n}} \text { or } \boldsymbol{b}^{*} \| \overrightarrow{\boldsymbol{n}}\end{array}$ & 20 to 400 & 13 \\
\hline & melt, nanorod & $\mathrm{N}$ & $\begin{array}{c}3{ }^{\circ} \mathrm{C} / \mathrm{min} \\
\text { or } 50^{\circ} \mathrm{C} / \mathrm{min}\end{array}$ & $<110>*$ or $<100>* \| \overrightarrow{\boldsymbol{n}}$ & $\begin{array}{c}25,35,65 \& \\
200 \\
\end{array}$ & 34 \\
\hline \multirow{3}{*}{$s \mathrm{PS}$} & melt, nanorod & $\mathrm{Y}$ & $255^{\circ} \mathrm{C}$ & $c \perp \vec{n}$ & $32,80 \& 200$ & 18 \\
\hline & \multirow{2}{*}{ melt, nanorod } & \multirow{2}{*}{$\mathrm{N}$} & $260^{\circ} \mathrm{C}$ & $c \perp \overrightarrow{\boldsymbol{n}}$ ( $\beta$-form) & \multirow{2}{*}{$80 \& 200$} & \multirow{2}{*}{35} \\
\hline & & & $240^{\circ} \mathrm{C}$ & random $(\alpha$-form $)$ & & \\
\hline \multirow{3}{*}{$i \mathrm{PS}$} & \multirow{2}{*}{ melt, nanorod } & $\mathrm{Y}$ & $170 \circ \mathrm{C}$ & $<100>* \| \overrightarrow{\boldsymbol{n}}$ & 300 & 36 \\
\hline & & $\mathrm{Y}$ & $1 / 00^{\circ}$ & $<110>* /<100>* \| \overrightarrow{\boldsymbol{n}}$ & 65 & 30 \\
\hline & melt, nanorod, & $\mathrm{Y}$ & $170^{\circ} \mathrm{C}$ & mainly $c \perp \vec{n}$ & 65 & 37 \\
\hline PLLA & melt, nanorod & $\mathrm{N}$ & & $<110>* /<200>* \| \overrightarrow{\boldsymbol{n}}$ & $\begin{array}{l}40,75,200 \\
\quad \& 385 \\
\end{array}$ & 38 \\
\hline & molt ponotule & $\mathrm{N}$ & $20 \circ / \min$ & mainly $\boldsymbol{b} \| \overrightarrow{\boldsymbol{n}}$ ( $\beta$-phase) & $30 \& 70$ & 30 \\
\hline PBA & mert, nanotude & $\mathbf{N}$ & $200 / / m i n$ & nearly random ( $\beta$-phase) & 100 & 39 \\
\hline & melt, nanotube & $\mathrm{N}$ & $33^{\circ} \mathrm{C}$ or $35^{\circ} \mathrm{C}$ & mainly $\boldsymbol{b} \| \overrightarrow{\boldsymbol{n}}$ ( $\alpha$-phase) & $100 \& 200$ & 40 \\
\hline P3HT & solution nanotube & $\mathrm{N}$ & as-prepared & $b \| \vec{n}$ & 240 & 41 \\
\hline & & & annealed at & \begin{tabular}{l||l||}
$\boldsymbol{b}$ & $\overrightarrow{\boldsymbol{n}}$ (majority) or $\boldsymbol{a}$ \\
\end{tabular} & & \\
\hline
\end{tabular}




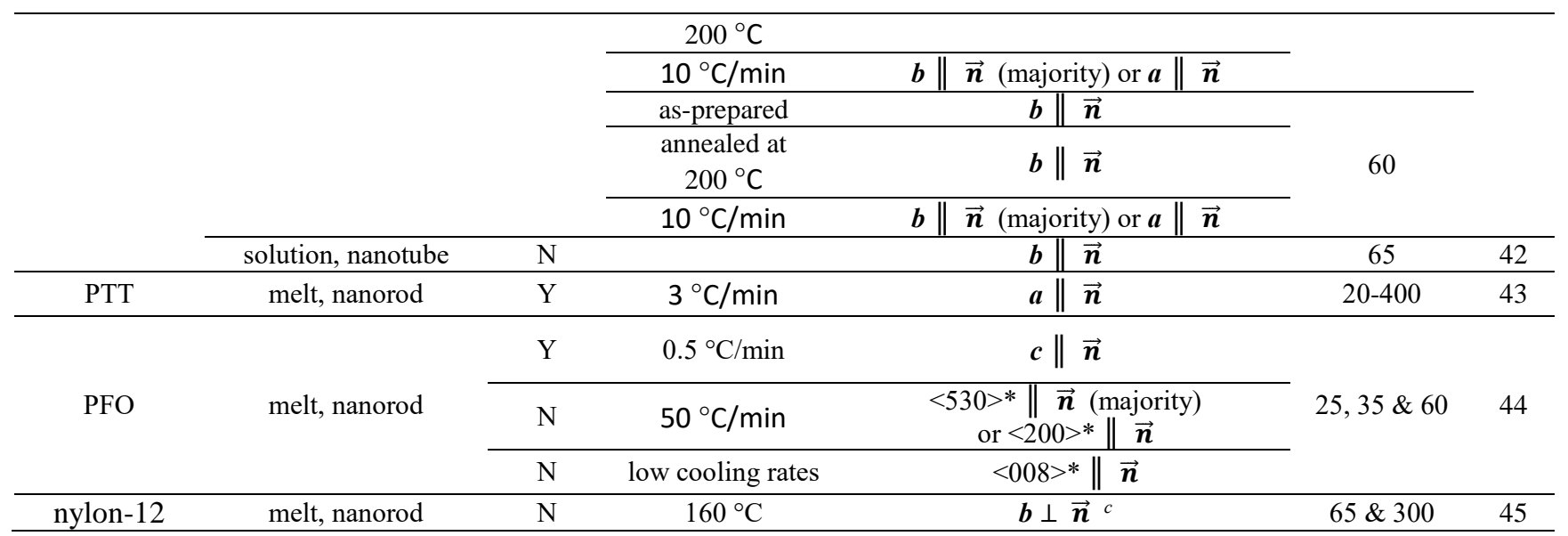

${ }^{a}$ The letter "N" is an abbreviation for "No" and "Y" is an abbreviation for "Yes".

${ }^{b}<h k l>*$ indicates the direction in reciprocal space, which is normal to the $(h k l)$ plane in real space. The $\overrightarrow{\boldsymbol{n}}$ represents the pore axis, which is normal to the surface plane of the AAO template.

${ }^{c}$ The chain axis is defined as $b$-axis in nylon- 12 .

\section{EXPERIMENTAL SECTION}

\subsection{Materials and Sample Preparation}

Close to monodisperse poly(ethylene oxide) (PEO), with number-average molecular weight of $10,000 \mathrm{~g} / \mathrm{mol}$ and polydispersity of 1.05, was purchased from Polymer Source Inc. The AAO templates with pore diameters of 40 , 100 and $400 \mathrm{~nm}$, and pore lengths of 100, 50, 20 and $5 \mu \mathrm{m}$ were prepared by a two-step electrochemical anodization of aluminum as described in our previous paper. ${ }^{13}$

Before infiltration with PEO solution, the AAO templates were washed with acetone and ethanol to remove possible impurities. The concentration of the PEO chloroform solution was $10 \mathrm{mg} / \mathrm{ml}$. The solution was drop casted on the AAO templates and dried in air. Then the AAO templates were treated at $100{ }^{\circ} \mathrm{C}$ under vacuum for 1 hour to remove residual solvent. The casting-heating process was repeated several times to ensure that the nanopores were fully infiltrated. The residual PEO on the surface of AAO templates was removed using a polish cloth to ensure the separate crystallization of PEO within the nanopores. Unless specified, the samples were crystallized at a constant cooling rate of $10^{\circ} \mathrm{C} / \mathrm{min}$.

\subsection{Characterization}

Thermal analysis was conducted with a differential scanning calorimeter (DSC Q2000, TA). The instrument 
was calibrated with indium before measurements. The samples of $\sim 5 \mathrm{mg}$ with the aluminum base were weighed, and encapsulated in aluminum pans for DSC measurements. All the samples were first heated to $100{ }^{\circ} \mathrm{C}$ and held for 3 min to eliminate the thermal history. Then the samples were scanned from 100 to $-50{ }^{\circ} \mathrm{C}$ at a cooling and heating rate of $10^{\circ} \mathrm{C} /$ min under high purity nitrogen atmosphere.

2D Wide angle X-ray diffraction (WAXD) measurements were carried out at room temperature on a Xeuss 2.0 SAXS/WAXS system (Xenocs SA, France). CuK $\alpha$ X-ray source (GeniX3D Cu ULD), generated at $50 \mathrm{kV}$ and 0.6 $\mathrm{mA}$, was utilized to produce X-ray radiation with a wavelength of $1.5418 \AA$. A semiconductor detector (Pilatus 300 K, DECTRIS, Swiss) with a resolution of $487 \times 619$ pixels (pixel size $=172 \times 172 \mu \mathrm{m}^{2}$ ) was used to collect the scattering signals. The scattering geometry is indicated in Figure 1. The $\psi$ angle and $\varphi$ angle are all set to $0^{\circ}$. The X-ray irradiates the sample along the $\mathrm{x}$-axis with an incident angle of $3^{\circ}$ with respect to the AAO surface. The $2 \mathrm{D}$ detector is placed perpendicular to the incident beam. The exposure time for each pattern is 5 min. The one-dimensional intensity profiles were integrated from the 2D WAXS patterns, averaged along the azimuthal angle.

The pole figures were measured with D8 DISCOVER X-ray diffractometer (Bruker) in reflection geometry. The wavelength of the radiation was $1.5406 \AA$. A 1D detector, the Bruker LYNXEYE, was employed to collect the intensity. Prior to the pole figure measurement, a specular scan was carried out to confirm the $2 \theta$ angle of the reflections. The diffraction angles were set as $19.1^{\circ}$ and $23.3^{\circ}$ for the two strongest reflection peaks (120) and $(112) /(032) /(\overline{13} 2) /(\overline{21} 2)$, respectively. ${ }^{46}$ These crystal planes have similar $d$-spacing of about $0.39 \mathrm{~nm}$. Figure 1 shows a schematic of the measurement geometry. The sample was mounted on top of a sample stage on an Eulerian cradle. During measurement, the sample rotated stepwise around the $z(\overrightarrow{\boldsymbol{n}})$ axis ( $\varphi$ angle) and the $x$ axis ( $\psi$ angle). The range of $\psi$ was set from $0^{\circ}$ to $80^{\circ}$ with an angular interval of $5^{\circ}$ and the exposure time of $10 \mathrm{~s}$. 


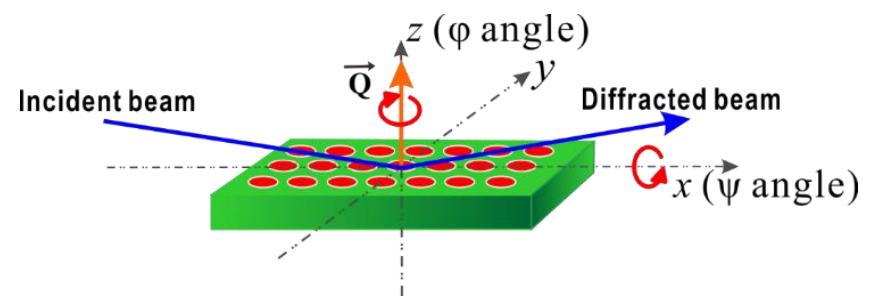

Figure 1. Schematic diagram of the experimental setup for pole figure measurement.

\section{RESULTS AND DISCUSSION}

\subsection{DSC and WAXD}

(a)

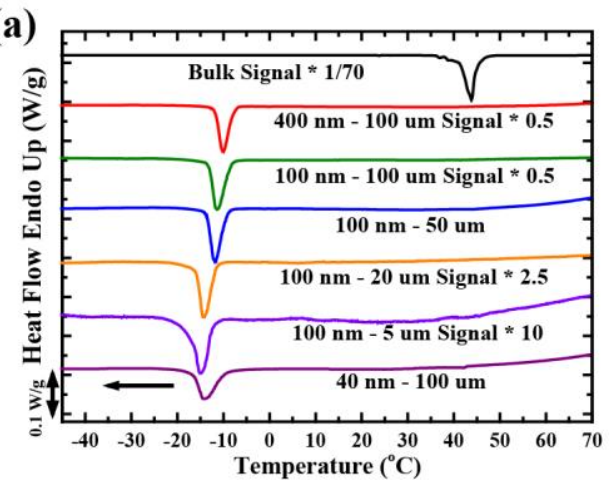

(c)

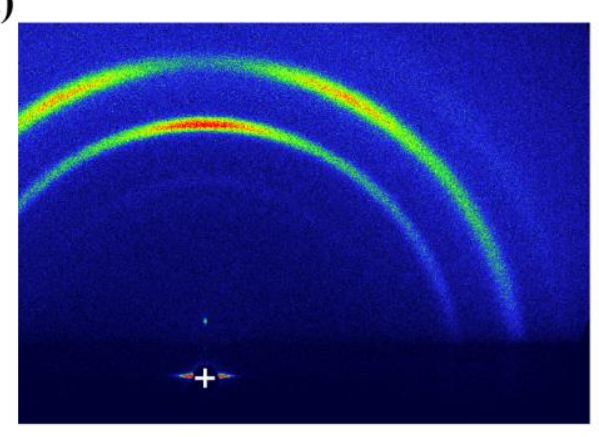

(b)

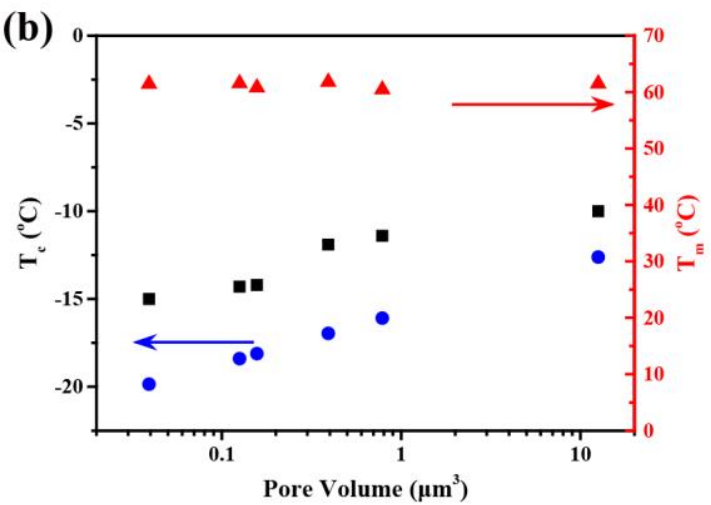

(d)

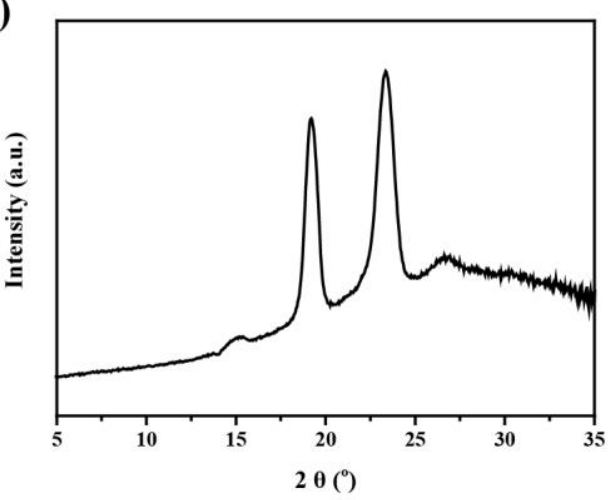

Figure 2. (a) DSC cooling curves of infiltrated PEO in AAO templates with different pore size. (b) Crystallization temperature ( $T_{\mathrm{c}}$, black square), calculated $T_{\mathrm{c}}$ (blue sphere) and melting temperature $\left(T_{\mathrm{m}}\right.$, red triangle) of infiltrated PEO in AAO as a function of pore volume. (c) 2D WAXD pattern of PEO confined within the AAO template with pore depth of $100 \mu \mathrm{m}$, and pore diameter of $100 \mathrm{~nm}$. The beam center is represented by a white cross. (d) Corresponding 1D intensity profile of the infiltrated PEO, obtained by averaging the intensity along the azimuthal angle. 
Figure 2a shows that all the samples crystallized at very large supercoolings, which agrees with previous reports. ${ }^{12,22}$ Only one peak is observed for all the samples, indicating that the number of nanopores without any active nucleating heterogeneity for PEO is much larger than the number of such heterogeneities in bulk $\mathrm{PEO}^{3}$. Therefore, the overwhelming majority of the nanopores did not contain heterogeneous nucleation sites and no surface film that could percolate pores was formed in any of the infiltrated AAO templates. ${ }^{13}$ The crystallization/melting temperatures, as a function of pore volume, are plotted in Figure 2b. A very clear trend can be observed, that is, the crystallization temperature of the samples decreases with pore volume. The estimated $T_{\mathrm{c}}$ according to the empirical formula obtained by Müller et al. for homogenously nucleated PEO phases within block copolymers and for PEO droplets, $T_{\mathrm{c}}\left({ }^{\circ} \mathrm{C}\right)=-41.8+2.89 \log \left(V_{\mathrm{d}}\left(\mathrm{nm}^{3}\right)\right)$, was also plotted in Figure $2 \mathrm{~b} .{ }^{3}$ The $T_{\mathrm{c}}$ values differ only about $2 \sim 4{ }^{\circ} \mathrm{C}$. Therefore, as previously reported for PEO, homogeneous nucleation probably occurs inside the volume of infiltrated material without any influence of the alumina surface. ${ }^{47,48}$ The $T_{\mathrm{m}}$ values are nearly constant, indicating the crystals have similar thermodynamic stability, which agrees with previous reports. ${ }^{13}$, 22

A typical 2D WAXD pattern of infiltrated PEO is shown in Figure 2c and the corresponding intensity profile is plotted in Figure 2d. The (120) reflection locates on the meridian and the $(112) /(032) /(\overline{13} 2) /(\overline{21} 2)$ reflection locates mainly on the off-meridian area. The basic features of the 2D pattern agree well with the previous reports. ${ }^{12,20,22}$ Although the pattern only covers a slice of the reciprocal space depending on the scattering vector, such pattern has been interpreted as an evidence for the $<120>*$ direction of the PEO crystals aligning parallel to the pore axis $(<120>* \| \overrightarrow{\boldsymbol{n}}) \cdot{ }^{20,21,22}$

\subsection{Pole Figures of Infiltrated PEO}

The pole figures corresponding to (120) and $(112) /(032) /(\overline{13} 2) /(\overline{21} 2)$ reflections of the infiltrated PEO crystals in AAO templates with different diameters are shown in Figure 3. The depth of the templates $(100 \mu \mathrm{m})$ and the 
thermal history of the samples $\left(10^{\circ} \mathrm{C} / \mathrm{min}\right.$ cooling) are the same. The intensity of the (120) pole figures show maximum values at $\psi=0^{\circ}$, which means that the (120) crystal plane normal is preferentially aligned parallel to the pore axis. The pole figures of $(112) /(032) /(\overline{13} 2) /(\overline{21} 2)$ reflections resemble rings with maxima located at $\psi \approx 30^{\circ}$. As shown in Table 2, the crystal planes with similar $d$-spacings, occasionally, have similar inclination angle with respect to the (120) plane within the range of $34-35^{\circ}$. Therefore, the pole figures agree with the texture that the (120) plane normal or the $\langle 120\rangle^{*}$ in reciprocal space align with the pore axis. The (120) crystal plane is the fastest growth plane in PEO. ${ }^{49,50,51,52}$ Therefore, the commonly reported result that the maximum growth direction aligns along the pore axis is confirmed, which agrees with the texture of PEO crystals in strongly segregated block copolymers crystallized at low supercoolings. ${ }^{17}$

Table 2: The Angle between Different Crystal Planes in PEO.

\begin{tabular}{c|c|c|c|c|c|c|c}
\hline plane & 120 & 112 & 032 & $\overline{13} 2$ & $\overline{21} 2$ & 100 & 010 \\
\hline$d$-spacing $(\AA)$ & 4.624 & 3.856 & 3.812 & 3.786 & 3.775 & 6.560 & 13.04 \\
$2 \theta\left({ }^{\circ}\right)$ & 19.2 & 23.0 & 23.3 & 23.5 & 23.6 & 13.5 & 6.77 \\
angle to $(120)\left(^{\circ}\right)$ & 0 & 34.7 & 35.1 & 33.9 & 34.7 & 45.2 & 44.8 \\
angle to $(100)\left(^{\circ}\right)$ & 45.2 & 29.6 & 73.8 & 72.5 & 28.9 & 0 & 90 \\
angle to $(010)\left(^{\circ}\right)$ & 44.8 & 72.8 & 28.7 & 29.4 & 73.2 & 90 & 0 \\
\hline
\end{tabular}

The influence of pore diameter is examined first, for which the templates have the same depth and the same thermal history. The general feature of those pole figures are similar. The orientation condition can be seen more clearly in the intensity profiles along $\psi$ obtained by averaging circularly along $\varphi$ angles (see Figure 4). It is shown that, as pore diameter decreases, the degree of orientation remains very similar. This is in accordance with our previous study, ${ }^{22}$ where the orientation of the crystal planes basically remains the same as the pore diameter is varied above a critical value. Another noteworthy feature is that a shoulder peak at $\psi=45^{\circ}$ appeared for the (120) reflection for the sample with $400 \mathrm{~nm}$ AAO (arrow in the figure).

The tilted (120) orientation has been observed recently by Liu and Chen, ${ }^{20,21}$ where they explained it by the possible "double constrains" imposed by the AAO wall and by the neighboring crystallites when the nucleation 
density is high. Although apparently possible, however, this model could not fully explain why the tilt angle $\left(45^{\circ}\right)$ was independent of crystallization temperatures (i.e., nucleation densities), molecular weights, and pore diameters, all of which are expected to influence the "strength" of the constrains caused by the neighboring crystallites. The tilt angle seems more like an intrinsic property of the PEO crystal rather than an environmental or kinetic effect. To account for the above observations, therefore, we propose an alternative explanation. Table 2 lists the angles between different crystal planes in PEO, calculated according to the unit cell parameters proposed by Takahashi and coworkers. ${ }^{53}$ It is interesting to find that the angle between (120) plane and (100) or (010) plane happened to be $45^{\circ}$. According to crystal growth studies on PEO, it has been reported that the (010) crystal plane is another fast growth plane of PEO..$^{50,51,52}$ If a minor PEO crystal population assembles within the AAO templates with the $<010>*$ parallel to the pore axis $\left(<010>^{*} \| \overrightarrow{\boldsymbol{n}}\right)$, the reflection of (120) plane of those crystals will exhibit a $45^{\circ}$ tilt angle with respect to the pore axis, thereby satisfactorily explaining the observed results.
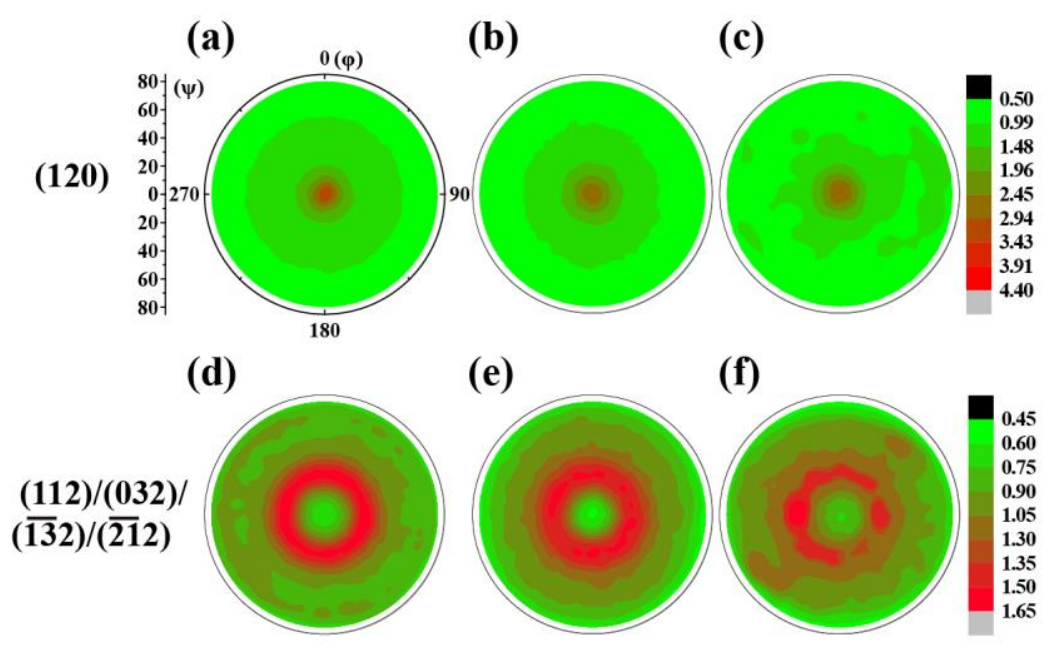

Figure 3. Pole figures of $(\mathrm{a}-\mathrm{c})$ the (120) reflections, and (d - f) the (032) reflections of infiltrated PEO in AAO templates with pore depth of $100 \mu \mathrm{m}$, and pore diameters of (a, d) $400 \mathrm{~nm}$, (b, e) $100 \mathrm{~nm}$, and (c, f) $40 \mathrm{~nm}$. 

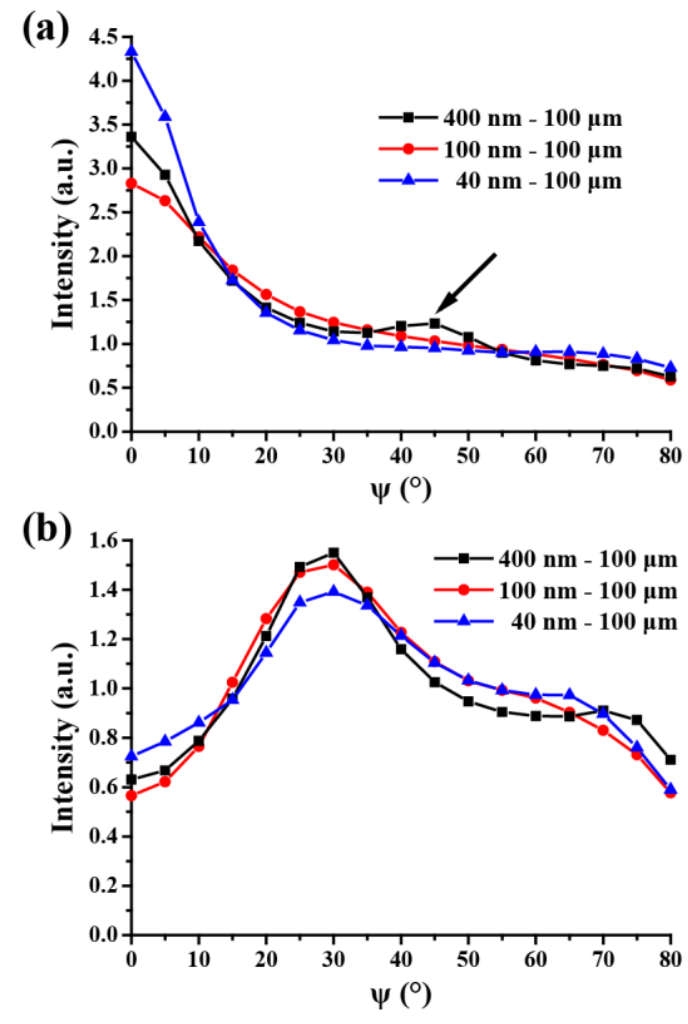

Figure 4. Azimuthal profiles of (a) the (120) reflections, and (b) the (032) reflections of infiltrated PEO in AAO templates with pore depth of $100 \mu \mathrm{m}$, and pore diameters of $400 \mathrm{~nm}, 100 \mathrm{~nm}$, and $40 \mathrm{~nm}$.

\subsection{Effect of Pore Depth}

There are few studies concerning the effect of pore depth which influences the volume and shape of the pore and may influence the crystal orientation as well. In extreme cases when the pore depth is very small, a transition from $2 \mathrm{D}$ to $3 \mathrm{D}$ confinement would occur and the crystallites would be statistically random. Figure 5 shows the pole figures of PEO crystal planes confined in AAO with the same diameter $(100 \mathrm{~nm})$ and different pore depths $(100,50$, 20, and $5 \mu \mathrm{m}$ ), while the azimuthal profiles are shown in Figure 6.

Before the pole figure measurements, the samples were first held at $100{ }^{\circ} \mathrm{C}$ for $3 \mathrm{~min}$ to erase their thermal history, and then crystallized at a cooling rate of $10{ }^{\circ} \mathrm{C} / \mathrm{min}$. The features of the pole figures are very similar, exhibiting predominately the $\langle 120>* \| \overrightarrow{\boldsymbol{n}}$ texture. The azimuthal profiles indicate that the degree of orientation increases with pore depth and thus confirms our hypothesis, although the smallest depth of the pores $(5 \mu \mathrm{m})$ is still 
sufficiently large as compared with the diameter $(100 \mathrm{~nm})$.

(a)

(120)

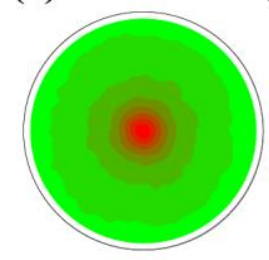

(e)

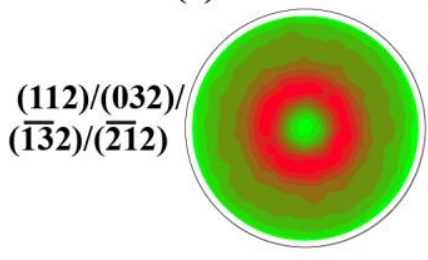

(b)

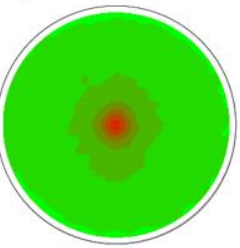

(f)

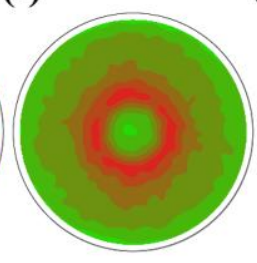

(c)

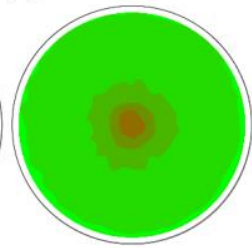

(g)

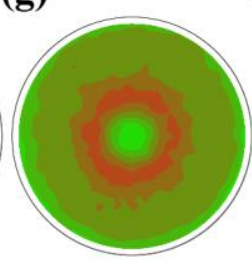

(d)

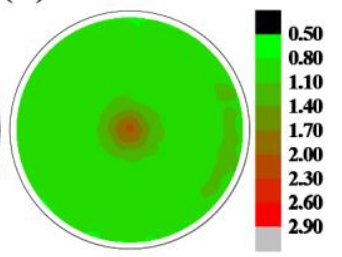

(h)

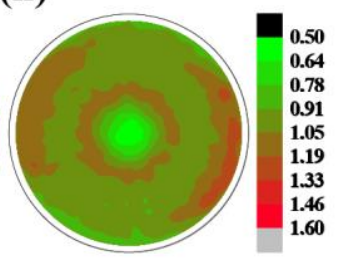

Figure 5. Pole figures of $(\mathrm{a}-\mathrm{d})$ the (120) reflections, and $(\mathrm{e}-\mathrm{h})$ the $(032)$ reflections of infiltrated PEO in AAO templates with pore diameter of $100 \mathrm{~nm}$, and pore depths of (a, e) $100 \mu \mathrm{m},(\mathrm{b}, \mathrm{f}) 50 \mu \mathrm{m},(\mathrm{c}, \mathrm{g}) 20 \mu \mathrm{m}$, and (d, h) 5 $\mu \mathrm{m}$.
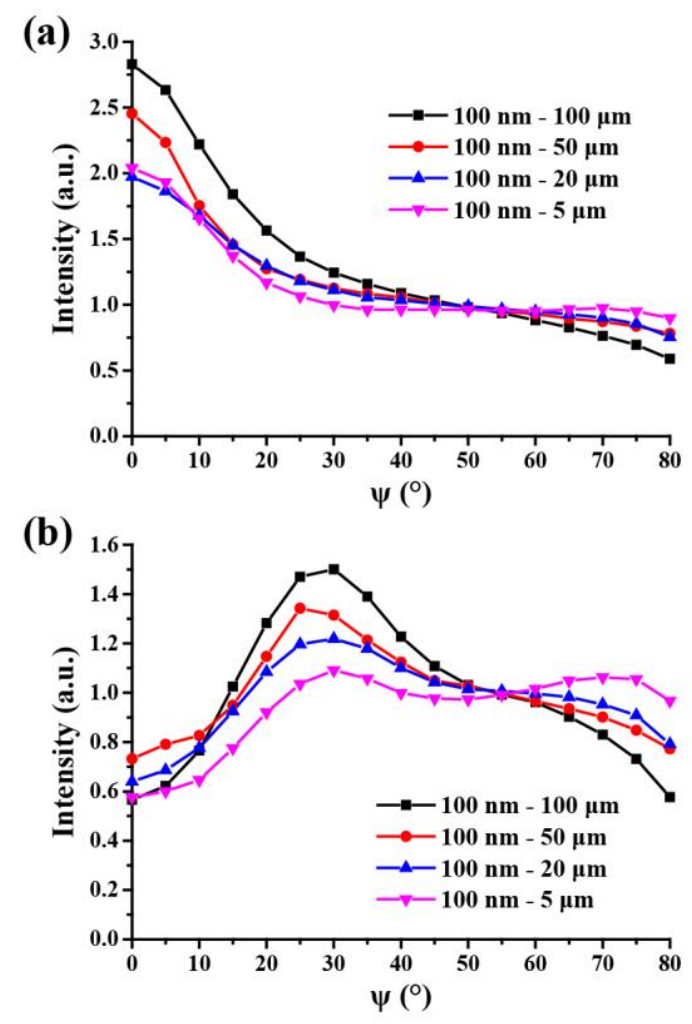

Figure 6. Azimuthal profiles of the (120) reflection (a) and the (032) reflection (b) of infiltrated PEO in AAO templates with pore diameter of $100 \mathrm{~nm}$, and pore depths of $100 \mu \mathrm{m}, 50 \mu \mathrm{m}, 20 \mu \mathrm{m}$, and $5 \mu \mathrm{m}$. 


\subsection{Effect of Cooling Rate}

It could be clearly seen in Figure S1 (supporting information) that the crystallization temperature decreased with the increase of cooling rate, and only one crystallization peak was observed for all the cooling rates. Figure 7 shows the pole figures of infiltrated PEO in AAO templates with different cooling rates. Once more, the general feature of the orientation mode is the same. However, the degree of orientation significantly decreases when the sample is quenched in liquid nitrogen. This is more pronounced in the azimuthal profiles of the pole figures (see Figure 8).

The cooling rate influences the interplay between nucleation rate and crystal growth rate, therefore, it has a strong influence on the developed crystalline texture. Since the PEO nucleates homogeneously within AAO, at lower cooling rates or higher isothermal crystallization temperatures, nucleation is the dominating step and crystal growth proceeds almost instantaneously. Under this circumstance, the crystallization kinetics would be first order with an Avrami index of 1.,54 With the increase of cooling rate or decrease of crystallization temperature, the nucleation rate will increase and the growth rate will decrease relative to one another. Under the extreme condition of ultra-high nucleation rate, many nuclei will form simultaneously within in one pore and the crystals grow little before they impinge with adjacent crystals. In this case, the nuclei will not "feel" the restricted geometry, hence isotropic texture would be observed. This is most obvious in the quenched sample.
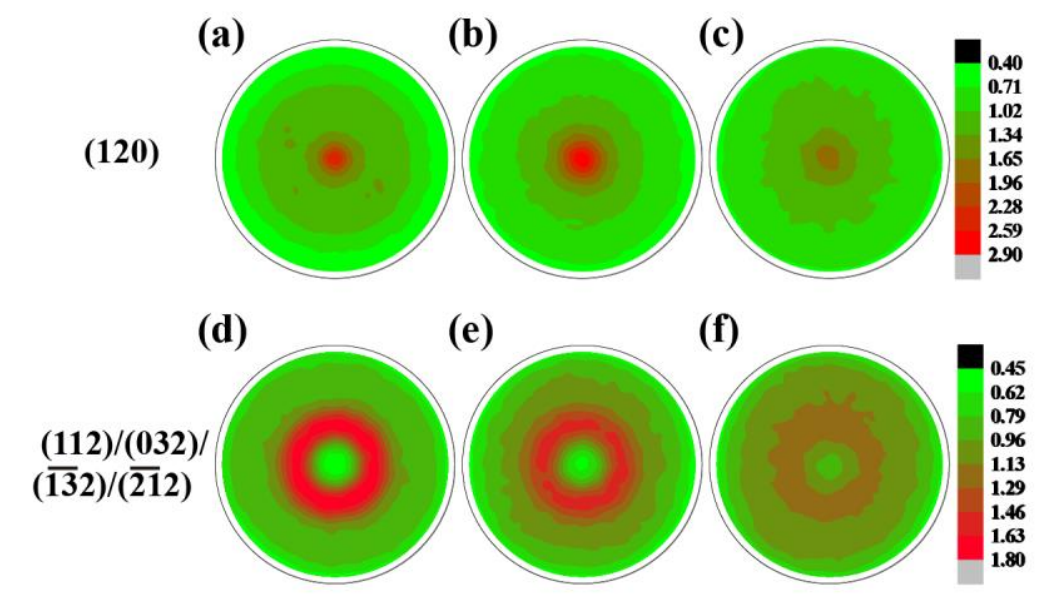

Figure 7. Pole figures of $(\mathrm{a}-\mathrm{c})$ the (120) reflections, and $(\mathrm{d}-\mathrm{f})$ the $(032)$ reflections of infiltrated PEO in AAO 
template with the pore diameter of $100 \mathrm{~nm}$, and pore depth of $100 \mu \mathrm{m}$, crystallized at different cooling rate. (a, d) crystallized at a cooling rate of $1{ }^{\circ} \mathrm{C} / \mathrm{min},(\mathrm{b}, \mathrm{e})$ crystallized at a cooling rate of $10{ }^{\circ} \mathrm{C} / \mathrm{min}$, and (c, f) quickly quenched into liquid nitrogen.
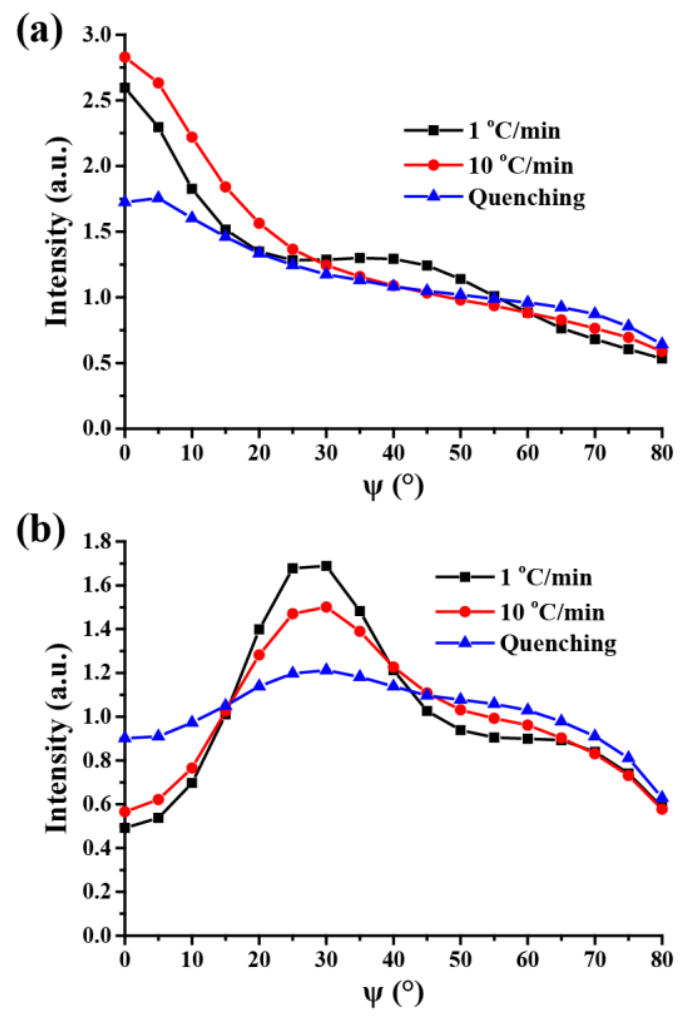

Figure 8. Azimuthal profiles of (a) the (120) reflections, and (b) the (032) reflections of infiltrated PEO in AAO template with the pore diameter of $100 \mathrm{~nm}$, and pore depth of $100 \mu \mathrm{m}$, crystallized at different cooling rate.

A closer look at Figure 8a shows that a small peak appears at $\psi=45^{\circ}$ in the azimuthal profile of the (120) reflection for the PEO infiltrated in the AAO template with a cooling rate of $1{ }^{\circ} \mathrm{C} / \mathrm{min}$. The fact that a lower cooling rate is beneficial for the $\langle 010\rangle^{*} \| \overrightarrow{\boldsymbol{n}}$ orientation probably indicates the different temperature dependence of the growth rates of different planes. It is probable that at a lower cooling rate, the growth rate of (010) plane is comparable to that of (120) plane. Thus a mixed structure of $\left\langle 120>^{*} \| \overrightarrow{\boldsymbol{n}} \text { and }<010\right\rangle^{*} \| \overrightarrow{\boldsymbol{n}}$ can be observed. Marentette et al. have shown in bulk PEO spherulites that the dominant crystal growth face transformed from (120) plane at lower supercoolings $\left(T_{\mathrm{c}}>51{ }^{\circ} \mathrm{C}\right)$ to $(010)$ plane at higher supercoolings $\left(T_{\mathrm{c}}<51{ }^{\circ} \mathrm{C}\right) .{ }^{52}$ However, no crystal 
growth data is available at extremely high supercoolings $\left(T_{\mathrm{c}}<-10^{\circ} \mathrm{C}\right)$.

Figure 9 shows the azimuthal profiles of the (120) pole figures of other samples. The PEO infiltrated in AAO with a diameter of $100 \mathrm{~nm}$ and a depth of $50 \mu \mathrm{m}$ (Figure 9a) exhibits similar features as in Figure 8. However, the $\psi$ $=45^{\circ}$ peak is not observed at all, even at the lowest cooling rate $\left(1^{\circ} \mathrm{C} / \mathrm{min}\right)$, for the sample with a smaller depth $(20$ $\mathrm{nm}$, Figure $9 \mathrm{~b}$ ). For the sample with $400 \mathrm{~nm}$ diameter and $100 \mu \mathrm{m}$ length, the $\psi=45^{\circ}$ is observed for both 1 and $10^{\circ} \mathrm{C} / \mathrm{min}$. The infiltrated PEO within AAO with $40 \mathrm{~nm}$ diameter and $100 \mu \mathrm{m}$ length does not show the $\psi=45^{\circ}$

(Figure 9d).
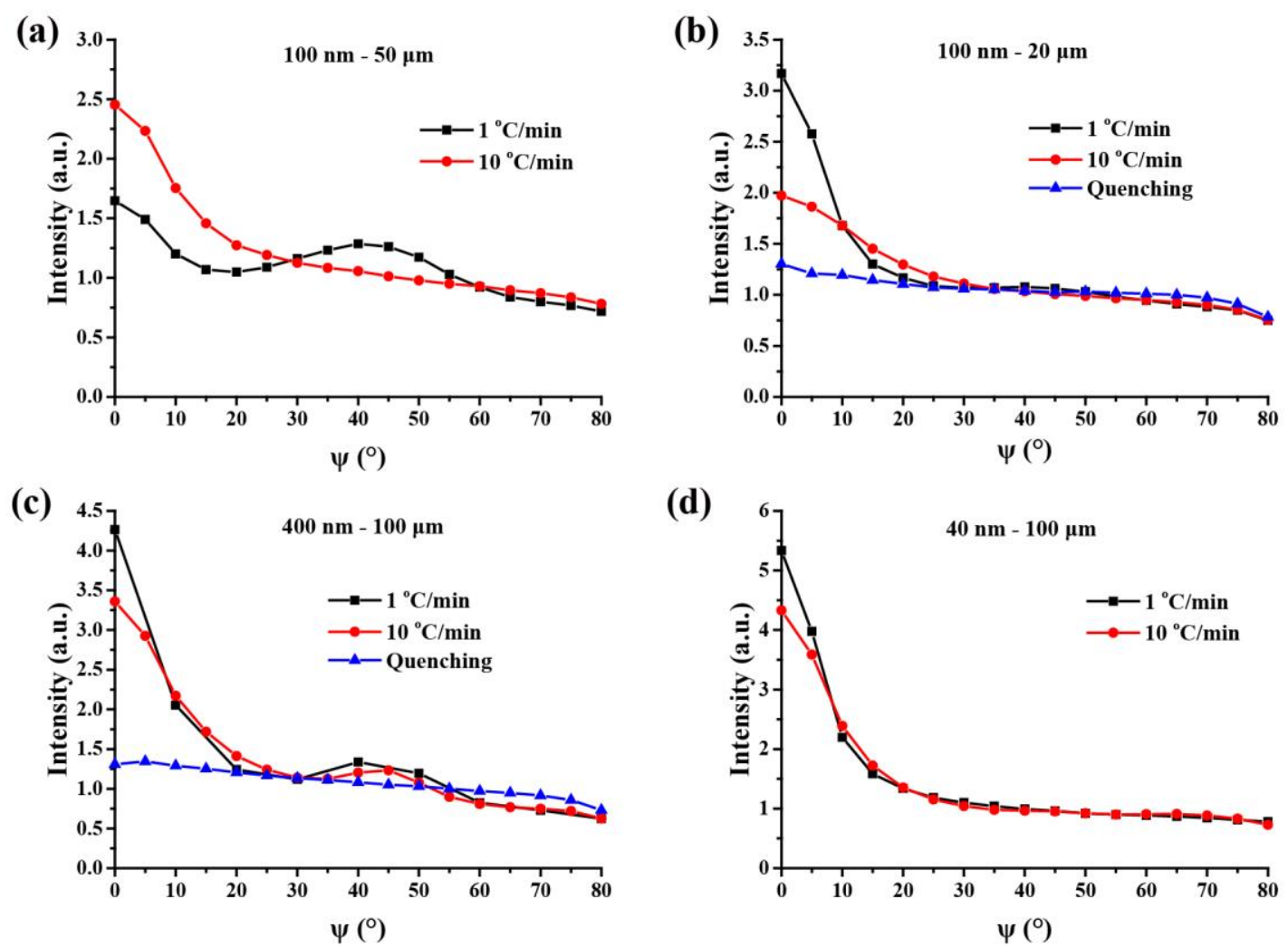

Figure 9. Azimuthal profiles of the (120) reflections of infiltrated PEO in AAO template with the pore diameter of $100 \mathrm{~nm}$, and pore depths of (a) $50 \mu \mathrm{m}$ and (b) $20 \mu \mathrm{m}$, and in AAO template with the pore depth of $100 \mu \mathrm{m}$, and pore diameters of (c) $400 \mathrm{~nm}$, and (d) $40 \mathrm{~nm}$, crystallized at different cooling rate. 


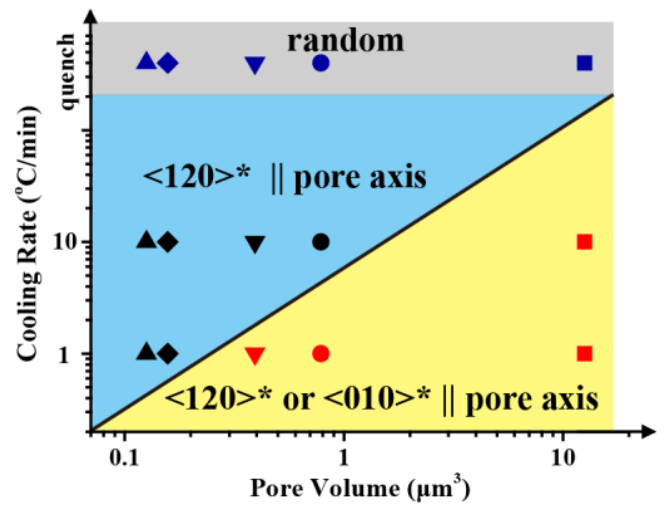

Figure 10. Diagram of the orientation mode of infiltrated PEO in AAO templates. The pore diameters and pore depths of the AAO templates were $400 \mathrm{~nm}-100 \mu \mathrm{m}$ (square), $100 \mathrm{~nm}-100 \mu \mathrm{m}$ (circle), $100 \mathrm{~nm}-50 \mu \mathrm{m}$ (down triangle), $100 \mathrm{~nm}-20 \mu \mathrm{m}$ (diamond), $40 \mathrm{~nm}$ - $100 \mu \mathrm{m}$ (up triangle), respectively.

The above results can be illustrated in an "orientation diagram" as shown in Figure 10. The diagram can be divided into three regions. Under super-high cooling rates (such as quenching), the nucleation density is extremely high, resulting in a random orientational texture, irrelevant to the size of the domains. When the cooling rates are lower, the texture of the samples are determined by kinetic effects, i.e., the fastest growth direction aligns parallel with the pore axis. Two textures are found at low cooling rates. In the top-left region with smaller pores and/or higher cooling rates, only the $\left\langle 120>^{*} \| \overrightarrow{\boldsymbol{n}}\right.$ mode is observed. The bottom-right region with larger pores and/or lower cooling rates exhibits mixed orientation modes of $<120>* \| \overrightarrow{\boldsymbol{n}}$ and $<010>* \| \overrightarrow{\boldsymbol{n}}$.

\subsection{Remarks on the Orientation Model}

Our results show that the orientation of infiltrated PEO in AAO templates agrees largely with the report of Huang et al. ${ }^{17}$ in cylinder-forming block copolymers containing PEO, which is different from the model proposed by Steinhart et al. ${ }^{15}$ in PVDF. Which model is more probable? A first look at Table 1 tells us that most of the reports fit the uniaxial/mixed orientation model. Probably, the PVDF is the only polymer where all (hk0) planes are able to grow under confinement. On the other hand, surface film residues of infiltrated polymers often manifest itself by showing multiple crystallization peaks. ${ }^{13}$ It is not clear how significant the residual polymer films on the surface of 
the AAO templates would influence the orientation of crystals.

Regardless of incompleteness, it is fairly safe to state "the chain axis is perpendicular to the pore axis". This allows the crystals to "rotate freely" around the chain axis, leading to the texture with all the (hk0) visible on the specular scan of XRD. Meanwhile, the crystals could also rotate freely around the pore axis. Except under super-high cooling rates, this statement seems always valid for crystallization under confinement governed by kinetics.

Another implication of the present work is that the crystal growth kinetics under very high supercoolings can be probed by studying the orientation feature of polymer confined in AAO, which is not possible for bulk samples. At least, the fastest growth plane could be readily read out. An important assumption is that the primary nuclei are randomly oriented. This is most likely true for homogeneous nucleation, still need to be explored in systems with surface nucleation.

\section{CONCLUSIONS}

In this work, a semi-quantitative study of the orientation of PEO confined in AAO templates was carried out for the first time by pole figure measurements. The influence of pore diameter, pore length and cooling rate was examined. Uniaxial orientation and mixed orientations were observed in PEO, in favor of the kinetic model proposing that the fastest growth direction aligns parallel to the pore axis. An "orientation diagram" was established to account for the two most important factors governing the crystal orientation texture. By quenching, crystallization of PEO within AAO was nucleation-controlled, exhibiting a random distribution of crystallites. Under low cooling rates, crystal growth rate played a decisive role on the crystal orientation. Relatively faster cooling rates and smaller pores lead to the $\langle 120>* \| \overrightarrow{\boldsymbol{n}}$ orientation. When the cooling rate was even lower, and/or the pores were larger, mixed orientations, with a coexistence of $\langle 120\rangle^{*} \| \overrightarrow{\boldsymbol{n}}$ and $\langle 010\rangle^{*} \| \overrightarrow{\boldsymbol{n}}$, was observed. The texture of the polymer within AAO provides hints on the crystal growth kinetics at high supercoolings which are 
inaccessible in bulk studies.

\section{ACKNOWLEDGEMENTS}

This work is supported by the National Natural Science Foundation of China (NSFC, 21873109, 51820105005, 21274156). G. L. is grateful to the Youth Innovation Promotion Association of the Chinese Academy of Sciences (2015026). G. L., D. W., and A. J. M. also acknowledge European funding by the RISE BIODEST project (H2020-MSCA-RISE-2017-778092). The authors thank Dr. Zhongkai Yang for assistance with pole figure measurement.

\section{Supporting Information}

Hermans' orientation parameter; DSC cooling curves of the infiltrated PEO in AAO template with different cooling rates; Crystallization temperature as a function of cooling rate.

\section{REFERENCES}

1 Samanta, P.; Liu, C. L.; Nandan, B.; Chen, H. L. Chapter 13 - Crystallization of Polymers in Confined Space A2 Thomas, Sabu. Crystallization in Multiphase Polymer Systems In: P MA, Gowd EB, Kalarikkal N, editors.: Elsevier; 2018. p 367-431.

2 Michell, R.M.; Blaszczyk-Lezak, I.; Mijangos, C.; Müller, A. J. Confined Crystallization of Polymers within Anodic Aluminum Oxide Templates. Journal of Polymer Science Part B: Polymer Physics 2014, 52(18), 1179-1194.

3 Müller, A. J.; Balsamo, V.; Arnal, M. L. Nucleation and Crystallization in Diblock and Triblock Copolymers. Advances in Polymer Science 2005, 190, 1-63.

4 Müller, M. L.; Arnal, M. L.; Lorenzo, A. T. Crystallization in Nano-Confined Polymeric Systems in Handbook of Polymer Crystallization, Piorkowska,E.; Rutledge, G. C. eds., John Wiley and Sons, Hoboken, New Jersey (USA), ISBN: 978-0-470-38023-9, 2013, 347-378 
5 Michell, R. M.; Müller, A. J. Confined Crystallization of Polymeric Materials. Progress in Polymer Science 2016, 54$55,183-213$.

6 Cheng, J. F.; Pu, H. T. Orientation of LDPE Crystals from Microscale to Nanoscale via Microlayer or Nanolayer Coextrusion. Chinese Journal of Polymer Science 2016, 34(12), 1411-1422.

7 Zhang, L. B.; Wang, K.; Zhu, J. T. Research Progress on Confined Assembly of Block Copolymers in China. Acta Polymerica Sinica 2017, 8, 1261-1276.

8 Masuda, H.; Fukuda, K. Ordered Metal Nanohole Arrays Made by a Two-Step Replication of Honeycomb Structures of Anodic Alumina. Science 1995, 268(5216), 1466-1468.

9 Michell, R. M.; Blaszczyk-Lezak, I.; Mijangos, C.; Müller, A. J. Confinement Effects on Polymer Crystallization: From Droplets to Alumina Nanopores. Polymer 2013, 54(16), 4059-4077.

$10 \mathrm{Wu}, \mathrm{H}$; Higaki, Y.; Takahara, A. Molecular Self-Assembly of One-Dimensional Polymer Nanostructures in Nanopores of Anodic Alumina Oxide Templates. Progress in Polymer Science 2018, 77, 95-117.

11 Duran, H.; Steinhart, M.; Butt, H.-J.; Floudas, G. From Heterogeneous to Homogeneous Nucleation of Isotactic Poly(propylene) Confined to Nanoporous Alumina. Nano Letters 2011, 11(4), 1671-1675.

12 Michell, R. M.; Lorenzo, A. T.; Müller, A. J.; Lin, M. C.; Chen, H. L.; Blaszczyk-Lezak, I.; Martin, J.; Mijangos, C. The Crystallization of Confined Polymers and Block Copolymers Infiltrated Within Alumina Nanotube Templates. Macromolecules 2012, 45(3), 1517-1528.

13 Shi, G. Y.; Liu, G. M.; Su, C.; Chen, H. M.; Chen, Y.; Su, Y. L.; Müller, A. J.; Wang, D. J. Reexamining the Crystallization of Poly(epsilon-caprolactone) and Isotactic Polypropylene under Hard Confinement: Nucleation and Orientation. Macromolecules 2017, 50(22), 9015-9023.

14 Steinhart, M.; Senz, S.; Wehrspohn, R. B.; Gosele, U.; Wendorff, J. H. Curvature-Directed Crystallization of Poly(vinylidene difluoride) in Nanotube Walls. Macromolecules 2003, 36(10), 3646-3651. 
15 Steinhart, M.; Goring, P.; Dernaika, H.; Prabhukaran, M.; Gosele, U.; Hempel, E.; Thurn-Albrecht, T. Coherent Kinetic Control over Crystal Orientation in Macroscopic Ensembles of Polymer Nanorods and Nanotubes. Physical Review Letters 2006, 97(2), 027801.

16 Loo, Y. L., Register, R. A. Crystallization within Block Copolymer Mesophases. Developments in Block Copolymer Science and Technology, 2004, 213.

17 Huang, P.; Zhu, L.; Cheng, S. Z. D.; Ge, Q.; Quirk, R. P.; Thomas, E. L.; Lotz, B.; Hsiao, B. S.; Liu, L. Z.; Yeh, F. J. Crystal Orientation Changes in Two-Dimensionally Confined Nanocylinders in a Poly(ethylene oxide)-b-polystyrene/Polystyrene Blend. Macromolecules 2001, 34(19), 6649-6657.

18 Wu, H.; Wang, W.; Huang, Y.; Su, Z. Orientation of Syndiotactic Polystyrene Crystallized in Cylindrical Nanopores. Macromolecular Rapid Communications 2009, 30(3), 194-198.

19 Maiz, J.; Martin, J.; Mijangos, C. Confinement Effects on the Crystallization of Poly(ethylene oxide) Nanotubes. Langmuir 2012, 28(33), 12296-12303.

20 Liu, C. L.; Chen, H. L. Variable Crystal Orientation of Poly(ethylene oxide) Confined within the Tubular Space Templated by Anodic Aluminum Oxide Nanochannels. Macromolecules 2017, 50(2), 631-641.

21 Liu, C. L.; Chen, H. L. Crystal Orientation of Poly(ethylene oxide) Confined Within the Nanorod Templated by Anodic Aluminum Oxide Nanochannels. Soft Matter 2018, 14(26), 5461-5468.

22 Guan, Y.; Liu, G. M.; Gao, P. Y.; Li, L.; Ding, G. Q.; Wang, D. J. Manipulating Crystal Orientation of Poly(ethylene oxide) by Nanopores. ACS Macro Letters 2013, 2(3), 181-184.

23 Maiz, J.; Schafer, H.; Rengarajan, G. T.; Hartmann-Azanza, B.; Eickmeier, H.; Haase, M.; Mijangos, C.; Steinhart, M. How Gold Nanoparticles Influence Crystallization of Polyethylene in Rigid Cylindrical Nanopores. Macromolecules 2013, 46(2), 403-412.

24 Shin, K.; Woo, E.; Jeong, Y. G.; Kim, C.; Huh, J.; Kim, K.-W. Crystalline Structures, Melting, and Crystallization of 
Linear Polyethylene in Cylindrical Nanopores. Macromolecules 2007, 40(18), 6617-6623.

25 Shingne, N.; Geuss, M.; Thurn-Albrecht, T.; Schmidt, H. W.; Mijangos, C.; Steinhart, M.; Martin, J. Manipulating Semicrystalline Polymers in Confinement. Journal of Physical Chemistry B 2017, 121(32), 7723-7728.

26 Martín, J.; Iturrospe, A.; Cavallaro, A.; Arbe, A.; Stingelin, N.; Ezquerra, T. A.; Mijangos, C.; Nogales, A. Relaxations and Relaxor-Ferroelectric-Like Response of Nanotubularly Confined Poly(vinylidene fluoride). Chemistry of Materials 2017, 29(8), 3515-3525.

27 Li, L.; Liu, J.; Qin, L.; Zhang, C.; Sha, Y.; Jiang, J.; Wang, X.; Chen, W.; Xue, G.; Zhou, D. Crystallization Kinetics of Syndiotactic Polypropylene Confined in Nanoporous Alumina. Polymer 2017, 110, 273-283.

$28 \mathrm{Wu}, \mathrm{H}$.; Wang, W.; Su, Z. H. Crystallization and Orientation of Polyethelene in Anodic Aluminum Oxide Templates. Acta Polymerica Sinica 2009, 5, 425-429.

29 Garcia-Gutierrez, M. C.; Linares, A.; Hernandez, J. J.; Rueda, D. R.; Ezquerra, T. A.; Poza, P.; Davies, R. J. Confinement-Induced One-Dimensional Ferroelectric Polymer Arrays. Nano Letters 2010, 10(4), 1472-1476.

30 Shingne, N.; Geuss, M.; Hartmann-Azanza, B.; Steinhart, M.; Thurn-Albrecht, T. Formation, Morphology and Internal Structure of One-Dimensional Nanostructures of the Ferroelectric Polymer P(VDF-TrFE). Polymer 2013, 54(11), 2737-2744

31 Wu, Y.; Gu, Q.; Ding, G.; Tong, F.; Hu, Z.; Jonas, A. M. Confinement Induced Preferential Orientation of Crystals and Enhancement of Properties in Ferroelectric Polymer Nanowires. ACS Macro Letters 2013, 2(6), 535-538.

32 Lutkenhaus, J. L.; McEnnis, K.; Serghei, A.; Russell, T. P. Confinement Effects on Crystallization and Curie Transitions of Poly(vinylidene fluoride-co-trifluoroethylene). Macromolecules 2010, 43(8), 3844-3850.

33 Reid, D. K.; Ehlinger, B. A.; Shao, L.; Lutkenhaus, J. L. Crystallization and Orientation of Isotactic Poly(propylene) in Cylindrical Nanopores. Journal of Polymer Science Part B: Polymer Physics 2014, 52(21), 1412-1419.

34 Suzuki, Y.; Duran, H.; Akram, W.; Steinhart, M.; Floudas, G.; Butt, H. J. Multiple Nucleation Events and Local 
Dynamics of Poly(epsilon-caprolactone) (PCL) Confined to Nanoporous Alumina. Soft Matter 2013, 9(38), 9189-9198.

35 Wu, H.; Wang, W.; Yang, H. X.; Su, Z. H. Crystallization and Orientation of Syndiotactic Polystyrene in Nanorods.

Macromolecules 2007, 40(12), 4244-4249.

36 Wu, H.; Cao, Y.; Ishige, R.; Higaki, Y.; Hoshino, T.; Ohta, N.; Takahara, A. Confinement-Induced Crystal Growth in One-Dimensional Isotactic Polystyrene Nanorod Arrays. ACS Macro Letters 2013, 2(5), 414-418.

37 Wu, H.; Su, Z. H.; Takahara, A. Isotactic Polystyrene Nanorods with Gradient Crystallite States. Soft Matter 2012, $8(11), 3180-3184$

38 Guan, Y.; Liu, G.; Ding, G.; Yang, T.; Müller, A. J.; Wang, D. Enhanced Crystallization from the Glassy State of Poly(l-lactic acid) Confined in Anodic Alumina Oxide Nanopores. Macromolecules 2015, 48(8), 2526-2533.

39 Sun, X. L.; Fang, Q. Q.; Li, H. H.; Ren, Z. J.; Yang, S. K. Effect of Anodic Alumina Oxide Pore Diameter on the Crystallization of Poly(butylene adipate). Langmuir 2016, 32(13), 3269-3275.

40 Mi, C.; Zhou, J.; Ren, Z.; Li, H.; Sun, X.; Yan, S. The Phase Transition Behavior of Poly(butylene adipate) in the Nanoporous Anodic Alumina Oxide. Polymer Chemistry 2016, 7(2), 410-417.

41 Xiang, W. Z.; Sun, X. L.; Ren, Z. J.; Zhang, J. M.; Li, H. H.; Yan, S. K. Diameter and Thermal Treatment Dependent Structure and Optical Properties of Poly(3-hexylthiophene) Nanotubes. Journal of Materials Chemistry C 2017, 5(32), $8315-8322$.

42 Byun, J.; Kim, Y.; Jeon, G.; Kim, J. K. Ultrahigh Density Array of Free-Standing Poly(3-hexylthiophene) Nanotubes on Conducting Substrates via Solution Wetting. Macromolecules 2011, 44(21), 8558-8562.

43 Martin-Fabiani, I.; Garcia-Gutierrez, M. C.; Rueda, D. R.; Linares, A.; Hernandez, J. J.; Ezquerra, T. A.; Reynolds, M. Crystallization Under One-Dimensional Confinement in Alumina Nanopores of Poly(trimethylene terephthalate) and Its Composites with Single Wall Carbon Nanotubes. ACS Applied Materials \& Interfaces 2013, 5(11), 5324-5329.

44 Martin, J.; Scaccabarozzi, A. D.; Nogales, A.; Li, R. P.; Smilgies, D. M.; Stingelin, N. Confinement Effects on the 
Crystalline Features of Poly(9,9-dioctylfluorene). European Polymer Journal 2016, 81, 650-660.

45 Cao, Y.; Wu, H.; Higaki, Y.; Jinnai, H.; Takahara, A. Molecular Self-Assembly of Nylon-12 Nanorods Cylindrically Confined to Nanoporous Alumina. IUCrJ 2014, 1, 439-445.

46 Takahashi, Y.; Tadokoro, H. Structural Studies of Polyethers, (-(CH2)m-O-)n. X. Crystal Structure of Poly(ethylene oxide). Macromolecules 1973, 6(5), 672-675.

47 Suzuki, Y.; Duran, H.; Steinhart, M.; Butt, H. J.; Floudas, G. Homogeneous Crystallization and Local Dynamics of Poly(ethylene oxide) (PEO) Confined to Nanoporous Alumina. Soft Matter 2013, 9(9), 2621-2628.

48 Suzuki, Y.; Steinhart, M.; Kappl, M.; Butt, H. J.; Floudas, G. Effects of Polydispersity, Additives, Impurities and Surfaces on the Crystallization of Poly(ethylene oxide)(PEO) Confined to Nanoporous Alumina. Polymer 2016, 99, 273-280.

49 Cheng, S. Z. D.; Chen, J. H. Nonintegral and Integral Folding Crystal Growth in Low - Molecular Mass Poly (ethylene oxide) Fractions. III. Linear Crystal Growth Rates and Crystal Morphology. Journal of Polymer Science Part B: Polymer Physics 1991, 29(3), 311-327.

50 Zhai, X. M.; Wang, W.; Zhang, G. L.; He, B. L. Crystal Pattern Formation and Transitions of PEO Monolayers on Solid Substrates from Nonequilibrium to near Equilibrium. Macromolecules 2006, 39(1), 324-329.

51 Zhang, G. L.; Cao, Y.; Jin, L. X.; Zheng, P.; Van Horn, R. M.; Lotz, B.; Cheng, S. Z. D.; Wang, W. Crystal Growth Pattern Changes in Low Molecular Weight Poly(ethylene oxide) Ultrathin Films. Polymer 2011, 52(4), $1133-1140$.

52 Marentette, J. M.; Brown, G. R. The (010)-(120) Crystal Growth Face Transformation in Poly(ethylene oxide) Spherulites. Polymer 1998, 39(6-7), 1405-1414.

53 Takahashi, Y.; Tadokoro, H., Structural Studies of Polyethers, (-(CH2)m-O-)n. X. Crystal Structure of Poly(ethylene oxide). Macromolecules 1973, 6 (5), 672-675.

54 Loo, Y. L.; Register, R. A.; Ryan, A. J. Polymer Crystallization in 25-nm Spheres. Physical Review Letters 2000, 
84(18), 4120-4123. 
For Table of Contents Use Only

Uniaxial and Mixed Orientations of Poly(ethylene oxide) in Nanoporous Alumina Studied by X-ray Pole Figure Analysis

Cui Su, Guangyu Shi, Xiaolu Li, Xiuqin Zhang, Alejandro J. Müller, Dujin Wang and Guoming Liu*

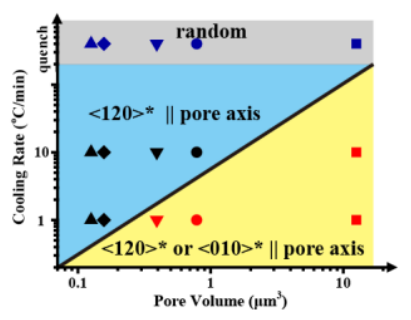

